\title{
International
}

\section{Journal of Medical and Exercise Science}

(Multidisciplinary, Peer Reviewed and Indexed Journal)

\section{ORIGINAL ARTICLE}

\section{A COMPARATIVE STUDY BETWEEN THE EFFICACY OF SWISS BALL EXERCISE V/S PRESSURE BIOFEEDBACK TRAINING ON PAIN, MOBILITY AND FUNCTIONAL DISABILITY IN COMPUTER PROFESSIONALS WITH NON SPECIFIC NECK PAIN}

Search engine: www.ijmaes.org

\section{PARVATHY.S ${ }^{1}$, VAISHALI SREEJITH ${ }^{2}$}

Corresponding Author:

${ }^{1} \mathrm{MPT}$ - student, Bethany Navajeevan College of Physiotherapy, Thiruvananthapuram, Kerala, India. Mail id: Co Author:

${ }^{2}$ Vice-Principal, Bethany Navajeevan College of Physiotherapy, Thiruvananthapuram, Kerala, India.

\section{ABSTRACT}

Background and purpose: Neck pain is a communal problem in the computer professionals. Among $59 \%$ of WRMSDs (work related musculoskeletal disorder) reported annually in India $30 \%$ cases are of neck pain. It is already proven that swiss ball training and pressure biofeedback training are effective for reducing pain, improving muscle strength, and mobility other than conventional exercises. Till now no study had done to compare the effectiveness of swiss ball training $\mathrm{v} / \mathrm{s}$ pressure biofeedback training on pain, mobility and functional disability in nonspecific neck pain for computer professionals. Objectives of the study: To compare the effects of Swiss ball training $\mathrm{v} / \mathrm{s}$ pressure biofeedback training on neck pain neck, mobility and functional disability. Methods: 30 subjects fulfilling the inclusion criteria were divided into two equal groups. Group A underwent swiss ball neck exercises and Group B underwent pressure biofeedback training. Both groups were given chin tuck exercise, ultrasound and ergonomic advises. Interventions were conducted over 6 weeks, three sessions per week, sessions of 20-30 minutes. Outcomes were measured before and after the treatment. Result: pre-post-test within the group found effective in both groups. However, pressure biofeedback training group shows greater improvement than Swiss ball training group in computer professionals with nonspecific neck pain. Conclusion: This study concluded that both exercise program are effective in improving pain, mobility and functional ability but pressure biofeedback training was more effective among computer professionals with nonspecific neck pain.

Keywords: Computer professionals; nonspecific neck pain; pressure biofeedback training; Swiss ball exercise; pain; mobility; functional disability

Received on $10^{\text {th }}$ August 2017, Revised $19^{\text {th }}$ August 2017, Accepted on $28^{\text {th }}$ August 2017 


\section{INTRODUCTION}

Neck pain is defined as the pain in the head and neck region due to trauma, degenerative changes, mechanical or inflammatory disorders. "Non-specific Neck Pain" is referred as the Neck pain caused by habitual postures" ${ }^{\prime 1}$. Neck pain is can be multi factorial in origin with several risk factors contributing to its development. The long term, lower intensity stress and strain, trauma, overuse, and improper posture are believed to be the most important causative factor for neck pain ${ }^{2,32}$. Neck- shoulder pain, poor muscle strength, restricted mobility and functional disability are the most common problems seen in adult population with prolonged use of computer.

when workers use a computer for prolonged duration a FHP, rounded shoulder and trunk flexion may gradually develop into a fixed postural habit, and may also affect normal shoulder elevation, as elevation of the upper extremity requires the same amount of cervical spine extension.

A forward head posture (FHP) is commonly adopted by computer users, ${ }^{3,4}$ and approximately $60 \%$ of individuals with neck pain have FHP or significantly increased FHP because of using computer for more than 2 hours a day,6. It occurs when the head is anterior to the vertical line through the individual's center of gravity ${ }^{7}$. An upper cervical extension and a lower cervical flexion is seen in individuals with $\mathrm{FHP},{ }^{8}$ and this will cause lengthening and weakness of the anterior cervical muscles and shortening of the posterior regional structures ${ }^{7,21}$.

Early research on FHP suggested that deep cervical flexor muscle (DCF) is the key muscle play a major role in supporting and straightening the cervical spine ${ }^{9,21}$. The weakness of deep cervical flexor (DCF) muscle is found to be a causative or contributory factor in the pathogenesis of head and neck pain ${ }^{10}$. The impairment in DCF muscles could result in poor support and potential overload on the cervical structures insufficiency in the preprogrammed activation of cervical muscles $^{11,12}$. It has been theorized that when muscle performance is impaired, the balance between the stabilizers on the posterior aspect of the neck and the DCFs will be disrupted, resulting in loss of proper alignment and posture, which is then likely to contribute to cervical impairment ${ }^{13}$.

Reports suggests that in $70 \%$ of patients with chronic neck pain there is significant reduction in muscular strength and endurance of the sternocleidomastoid and deep cervical flexor (DCF) muscles ${ }^{14,31}$. The longus colli and longus capitis muscles of DCF play important roles in maintaining posture control and stability of the neck $^{15,31}$. The weak superficial and deep neck flexors and high-density muscle spindles reduce the ability to maintain a correct upright posture and cervical posture lead to a faulty forwarded neck posture. A prolonged computer user showed regions of local segmental instability when the superficial muscles of the neck were stimulated to produce movement in the nearupright and neutral postures ${ }^{16,17}$. Therefore, maintaining the muscular strength of the superficial and deep flexors is critical for controlling neck posture and stability.

Background and need of the study: Superficial and deep muscle strengthening is necessary to control the neck posture and stability. Swiss ball exercise and pressure biofeedback training is shown effectiveness in strengthening these 
muscles with added advantages. Till now no studies are available for the comparison of pressure biofeedback training and Swiss ball training for nonspecific neck pain in computer professionals. The purpose of the study is to implement the best treatment to relieve nonspecific neck pain on computer professionals

Objective of the study: Objective of the study was to Compare the effects of Swiss ball training and pressure feedback training on relieve pain, improving mobility and Improve functional ability in computer professionals with nonspecific neck pain.

\section{HYPOTHESIS}

Null hypothesis: There will be no significant difference in pain, mobility and disability in computer professionals between pressure biofeedback training group and Swiss ball training group.

Alternative hypothesis:There will be significant difference in pain, mobility and disability in computer professionals between pressure biofeedback training group and Swiss ball training group.

Study setting: Patients with nonspecific neck pain diagnosed and referred by a consultant Orthopaedician from Outpatient department, Bethany Navajeevan College of Physiotherapy and Software companies in and around, Trivandrum.

Study design: Pre v/s post Comparative study

Study duration:The study was conducted over a period of 12 months.

Sample size: 30 subjects who fulfilled the inclusion criteria were included in the study.

Sampling Procedure: Purposive Sampling
Materials and measurement tools: Swiss Ball, Pressure Biofeedback Device, Couch, Ultrasound, Consent form, Visual Analogue Scale, Goniometer, Neck Disability Index

Inclusion Criteria: Pain for more than one month, A regular user of computer for more than 5 hours per day for more than 2 years, had not been under any exercise therapy priorly, Age group between 20 - 35, Score on VAS of greater than 5, Mild to moderate disability score on the neck disability index, Both males and females

Exclusion Criteria: Cervical spondylosis, Any degenerative or disc changes, Recent fracture (less than) 1 year around neck, scapula and shoulder, Recent surgery around shoulder and neck, Cervicogenic headache, Any other pathological changes (eg. Spinal curve changes, klipelfiel syndrome etc), Malignant neoplasms, Vascular diseases, Significant neurological deficit, Spinal cord compression, Inflammatory disease of spine, Spinal infections, Cervical instability

Outcome Measure: Pain evaluated with visual analogue scale, Mobility measured with goniometer and Functional disability evaluated with Neck Disability Index Score.

\section{Statistical Tools:}

1. Wilcoxon Signed Rank Test - to compare the pretest and posttest values of Swiss ball exercise group and pressure biofeedback training group.

2. Mann Whitney Rank Test - to compare the posttest values between Swiss ball exercise group and pressure biofeedback training group.

Procedure: Based on the inclusion and exclusion criteria 30 subjects (computer 
professionals) with nonspecific neck pain were included in the study. They were divided equally in to two groups, group A (Swiss ball exercise group) group $B$ (pressure biofeedback training group). Once the permission has been granted by the subjects, they were explained about the study and the procedure contained written concern was also been taken. Following this a subjective assessment of the patient was done which includes name, age, gender, chief complaints, duration of the condition and history of the patient. After the patient's subjective assessment had been taken, he or she were assessed for pretest outcome measures.

\section{Swiss ball training ${ }^{19,23}$}

Swiss ball $(65 \mathrm{~cm})$ was given to the subjects. For strengthening the deep neck flexors, subjects lie supine on the Swiss ball with the foot on the floor then head up and chin-tucked in. Both hands were placed on the abdomen. The training consisted of 10 repetitions 10 - second holds in the first two weeks, followed by 15 second holds in the second two weeks and 15 repetitions with 15 second hold in the final two weeks. The subject was asked to perform the exercises 3 sessions per week for 6 weeks, a total of 18 sessions, each session lasting for 20 minutes for 1-3 weeks and 30 minutes for 3-6 weeks.

The progression was given by adding bridging on the ball with pulling the jaw down. This training consisted of 10 repetitions with 10 second hold in the 3-4 weeks and 15 repetitions with 10 second hold in the 5-6 weeks. The intensity is again increased by one leg raise from the floor and chin tuck. Here 10 repetitions with 10 second hold is given in the 5-6 weeks.

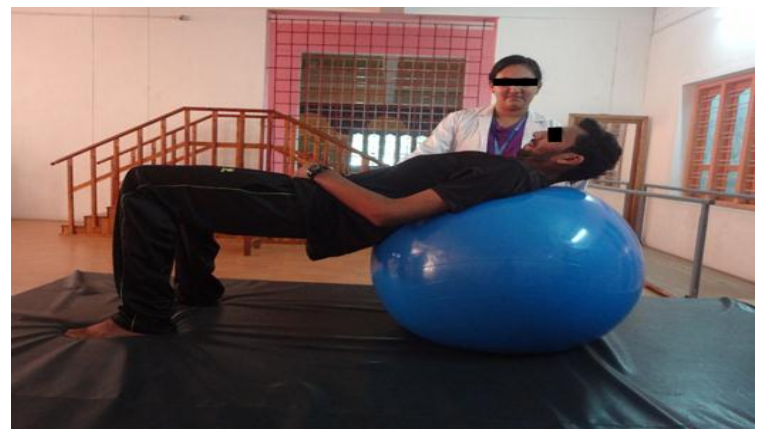

Figure 1: patient performing exercise in swiss ball

\section{Pressure biofeedback training ${ }^{18}$}

The pressure biofeedback device (stabilizer, Chattanooga Group) was positioned on the back head, and then flattened cervical lordosis was confirmed by using the visual feedback obtained via the dials of the device.

First, the air bag under the neck was inflated to $20 \mathrm{~mm} \mathrm{Hg}$, and then the subject presses the bag slightly with slight increments $(2 \mathrm{~mm} \mathrm{Hg})$ of pressure through the sensor dial to reach 22 $\mathrm{mm} \mathrm{Hg}$, contraction was maintained for about 10-15 seconds. This was repeated 10 times with 3-5 rest periods per session at the beginning and the time was extended by 2 to 3 seconds every 2 to 3 days until it reaches a value of 25 seconds. Progression was given by gradually increasing the pressure of the equipment by $2 \mathrm{~mm} \mathrm{Hg}$ from $20 \mathrm{mmHg}$ to 30 $\mathrm{mmHg}$. Training session is for a period of 6 weeks with 3 sessions per week, per session for 20 minutes for 1-3 weeks and 30 minutes for 3 6 weeks

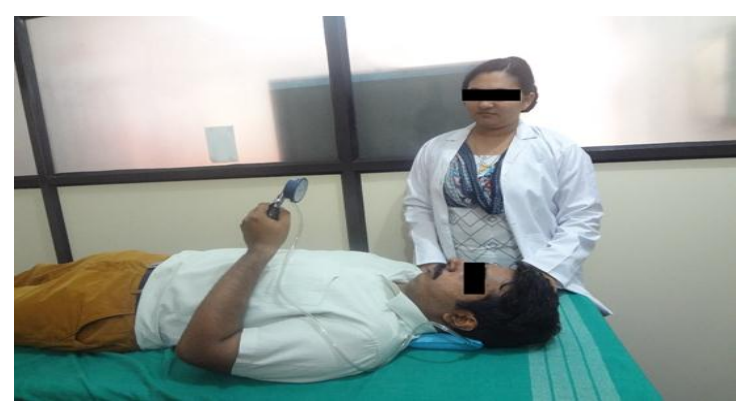

Figure 2: patient performing exercise in pressure biofeedback 
Both groups were given self-correction technique like chin tuck exercise 30 repetition per session, electrotherapy modalityultrasound ${ }^{33}$ and ergonomic advises. After the treatment of 6 weeks, the end results are recorded.

\section{Ergonomic advises ${ }^{32}$}

Adjust the height of patient's seat so that feet are resting firmly on the floor. Use a footrest if feel that feet are not supported properly.

The depth of seat should allow the back of knees to extend beyond the edge of the seat. Thighs should be approximately parallel to the floor.wrist should not be angled up or down.

Set the height of the work surface to work without straining or bending. Arrange commonly used items (stapler, phone etc.) so that they are within easy reach.

The top of one-third of the computer screen should be at or below the eye-level; the distances between eyes and the monitor should be 18 or more typically arm's length.

Document holder in line with front of the monitor. Height and angle adjustable for the comfort of the users.

Back is fully supported with appropriate lumbar support when sitting vertical or leaning back slight.

Shoulders are relaxed and upper limbs hangs normally at the side of the body.

\section{RESULT}

\section{Swissball training group}

\begin{tabular}{|c|c|c|c|c|c|c|c|}
\hline Outcome & & $\mathbf{N}$ & Mean & $\begin{array}{c}\text { Std. } \\
\text { Deviation }\end{array}$ & $\begin{array}{c}\text { Mean } \\
\text { difference }\end{array}$ & $Z$ value & $P$ value \\
\hline \multirow[t]{2}{*}{ VAS } & Pretest & 15 & 6.90 & .949 & \multirow[b]{2}{*}{3.43} & \multirow[b]{2}{*}{-3.455} & \multirow[b]{2}{*}{0.00} \\
\hline & Posttest & 15 & 3.47 & .694 & & & \\
\hline \multirow[t]{2}{*}{ NDIS } & Pretest & 15 & 16.60 & 1.682 & \multirow[b]{2}{*}{5.33} & \multirow{2}{*}{-3.438} & \multirow{2}{*}{0.00} \\
\hline & Posttest & 15 & 11.27 & 2.219 & & & \\
\hline \multirow{2}{*}{$\begin{array}{l}\text { Cervical } \\
\text { flexion ROM }\end{array}$} & Pretest & 15 & 36.73 & 6.431 & \multirow[b]{2}{*}{10.67} & \multirow{2}{*}{-3.414} & \multirow{2}{*}{0.00} \\
\hline & Posttest & 15 & 47.40 & 5.667 & & & \\
\hline \multirow{2}{*}{$\begin{array}{l}\text { Cervical } \\
\text { extension } \\
\text { ROM }\end{array}$} & Pretest & 15 & 40.87 & 3.796 & \multirow{2}{*}{9.13} & \multirow[b]{2}{*}{-3.418} & \multirow[b]{2}{*}{0.00} \\
\hline & Posttest & 15 & 50.00 & 4.209 & & & \\
\hline \multirow{2}{*}{$\begin{array}{l}\text { Right rotation } \\
\text { ROM }\end{array}$} & Pretest & 15 & 42.40 & 5.998 & \multirow[b]{2}{*}{23.67} & \multirow{2}{*}{-3.417} & \multirow{2}{*}{0.00} \\
\hline & Posttest & 15 & 66.07 & 5.982 & & & \\
\hline \multirow{2}{*}{$\begin{array}{l}\text { left rotation } \\
\text { ROM }\end{array}$} & Pretest & 15 & 43.47 & 4.794 & \multirow[b]{2}{*}{24.53} & \multirow{2}{*}{-3.415} & \multirow{2}{*}{0.00} \\
\hline & Posttest & 15 & 68.00 & 5.278 & & & \\
\hline
\end{tabular}

Table 1: Comparison of pretest and post test valuues of outcome measures in swissball training group 


\begin{tabular}{|c|c|c|c|c|c|c|c|}
\hline \multicolumn{8}{|c|}{ Pressure biofeedback training group } \\
\hline Outcome & & $\mathbf{N}$ & Mean & $\begin{array}{c}\text { Std. } \\
\text { Deviation }\end{array}$ & $\begin{array}{c}\text { Mean } \\
\text { difference }\end{array}$ & $Z$ value & $P$ value \\
\hline \multirow[t]{2}{*}{ VAS } & Pretest & 15 & 6.73 & .821 & \multirow[b]{2}{*}{4.16} & \multirow{2}{*}{-3.436} & \multirow{2}{*}{0.00} \\
\hline & Posttest & 15 & 2.57 & .753 & & & \\
\hline \multirow[t]{2}{*}{ NDIS } & Pretest & 15 & 19.33 & 2.820 & \multirow[b]{2}{*}{16.726} & \multirow{2}{*}{-3.421} & \multirow{2}{*}{0.00} \\
\hline & Posttest & 15 & 7.93 & 2.604 & & & \\
\hline \multirow{2}{*}{$\begin{array}{c}\text { Cervical flexion } \\
\text { ROM }\end{array}$} & Pretest & 15 & 36.73 & 6.017 & \multirow[b]{2}{*}{15} & \multirow{2}{*}{-3.418} & \multirow{2}{*}{0.00} \\
\hline & Posttest & 15 & 51.73 & 5.444 & & & \\
\hline \multirow{2}{*}{$\begin{array}{c}\text { Cervical } \\
\text { extension ROM }\end{array}$} & Pretest & 15 & 41.47 & 4.838 & \multirow[b]{2}{*}{18.26} & \multirow{2}{*}{-3.418} & \multirow{2}{*}{0.00} \\
\hline & Posttest & 15 & 59.73 & 4.847 & & & \\
\hline \multirow{2}{*}{$\begin{array}{l}\text { Right rotation } \\
\text { ROM }\end{array}$} & Pretest & 15 & 40.93 & 6.170 & \multirow[b]{2}{*}{30.47} & \multirow{2}{*}{-3.429} & \multirow{2}{*}{0.00} \\
\hline & Posttest & 15 & 71.40 & 5.054 & & & \\
\hline \multirow{2}{*}{$\begin{array}{l}\text { Left rotation } \\
\text { ROM }\end{array}$} & Pretest & 15 & 43.73 & 6.777 & \multirow[b]{2}{*}{1.998} & \multirow{2}{*}{-3.424} & \multirow{2}{*}{0.00} \\
\hline & Posttest & 15 & 72.87 & 4.779 & & & \\
\hline
\end{tabular}

Table 2: Comparison of pretest and post test valuues of outcome measures in pressure biofeeedback group

\begin{tabular}{|c|c|c|c|c|c|c|}
\hline Outcome & Training group & $\mathbf{N}$ & $\begin{array}{c}\text { Mean } \\
\text { Rank }\end{array}$ & $\begin{array}{l}\text { Sum of } \\
\text { Ranks }\end{array}$ & $\begin{array}{c}\text { U } \\
\text { Value }\end{array}$ & Significance \\
\hline \multirow[t]{2}{*}{ VAS } & Swiss Ball & 15 & 19.90 & 298.50 & \multirow{2}{*}{46.50} & \multirow[b]{2}{*}{.004} \\
\hline & Pressure Biofeedback & 15 & 11.10 & 166.50 & & \\
\hline \multirow[t]{2}{*}{ NDIS } & Swiss Ball & 15 & 20.43 & 306.50 & \multirow{2}{*}{38.50} & \multirow{2}{*}{.001} \\
\hline & Pressure Biofeedback & 15 & 10.57 & 158.50 & & \\
\hline \multirow{2}{*}{$\begin{array}{l}\text { Cervical flexion } \\
\text { ROM }\end{array}$} & Swiss Ball & 15 & 12.13 & 182.00 & \multirow{2}{*}{62.00} & \multirow{2}{*}{.035} \\
\hline & Pressure Biofeedback & 15 & 18.87 & 283.00 & & \\
\hline \multirow{2}{*}{$\begin{array}{l}\text { Cervical } \\
\text { extension ROM }\end{array}$} & Swiss Ball & 15 & 8.93 & 134.00 & \multirow[t]{2}{*}{14.00} & \multirow[b]{2}{*}{.000} \\
\hline & Pressure Biofeedback & 15 & 22.07 & 331.00 & & \\
\hline \multirow{2}{*}{$\begin{array}{l}\text { Right rotation } \\
\text { ROM }\end{array}$} & Swiss Ball & 15 & 11.83 & 177.50 & \multirow{2}{*}{57.50} & \multirow{2}{*}{.021} \\
\hline & Pressure Biofeedback & 15 & 19.17 & 287.50 & & \\
\hline \multirow{2}{*}{$\begin{array}{l}\text { Left rotation } \\
\text { ROM }\end{array}$} & Swiss Ball & 15 & 11.57 & 173.50 & \multirow{2}{*}{53.50} & \multirow{2}{*}{.013} \\
\hline & Pressure Biofeedback & 15 & 19.43 & 291.50 & & \\
\hline
\end{tabular}

Table 3: Comparison of oucome measures between swissball training group and pressure biofeedback training group 
The pre-test and post-test mean value tables (Table-1,2,3) shows that both group has significant improvement. Although improvement was seen in both groups, GroupB (pressure biofeedback training group) improved better compared to Group-A (Swiss ball training group).

\section{DISCUSSION}

Neck pain is a common health problem in the general population and especially among computer workers. Non-specific neck pain is a simple (non-specific) neck pain without specific underlying disease causing the pain. 59\% of WRMSDs (work related musculoskeletal disorder) reported annually by IT professionals in India, out of which $30 \%$ cases are of neck pain.

In a study conducted by Md. Nezamuddin et $\mathrm{al}^{18}$ on Efficacy of Pressure biofeedback for cervical flexors indicated that pressure biofeedback was an effective means for reducing pain. The findings reported that biofeedback could be useful alternative for musculoskeletal pain. Zaheen Ahmed Iqbal et $\mathrm{al}^{20}$ did a study on Effect of Deep Cervical Flexor Muscles Training Using Pressure Biofeedback on Pain and Disability of School Teachers with Neck Pain and he showed that addition of pressure biofeedback for deep cervical flexor muscles training gave a better result than conventional exercises alone. Similarly Dong Yeon Kang ${ }^{21}$ in his study proved that deep cervical flexor training with a pressure biofeedback unit is a useful method for maintaining neck mobility and muscular endurance in people with forward head posture. Another study by Myoung-Hyo Lee et $\mathrm{al}^{22}$ effectiveness in deep flexor musclestrengthening exercise on the neck- shoulder posture, and the strength and endurance of the deep flexor muscles of high-school students using pressure biofeedback device.

Similarly, in a study conducted by Jeoung Ah $A h n^{19}$ et al on Effect of stabilization exercise with Swiss ball on neck-shoulder pain showed that pain was significantly decreased by exercises on a Swiss ball, which also and increased neck flexion for stabilization of the neck. Exercises on a Swiss ball could be used selectively either for training or for stabilization of neck. Hye-Young Cho et $\mathrm{al}^{23}$ their study proved that Swiss Ball stabilisation exercise is likely to widen the CSA of deep and superficial muscles in patient with chronic neck pain, and can be an efficacious therapeutic method that can decrease numerical value of VAS and NDI. The purpose of this study was to compare the effectiveness of swiss ball exercises and pressure biofeedback training in computer professionals in the age group of $20-35$ years (showing mild to moderate disability in NDIS) with nonspecific neck pain in improving pain, mobility and functional ability.

30 subjects fulfilling the inclusion criteria were recruited in this study after obtaining an informed consent. The subjects were divided into two groups: Group A (swiss ball training group) and Group B (pressure biofeedback training group) with 15 subjects each. Each subject was well explained the procedure of the interventions and the possible risk factors involved. Group A underwent swiss ball neck stabilization exercises \& Group B underwent pressure biofeedback training for the DCFs. Both groups were given self-correction technique as chin tuck exercise 30 repetition per session, electrotherapy modalityultrasound and ergonomic advises. Interventions were conducted over 6 weeks, three sessions per week, sessions lasting up to 20- 30 minutes. All subjects were assessed for pain, cervical ROM and neck disability.

The outcome measures used in this study were Visual Analogue Scale (VAS) to measure pain, goniometer for range of motion and Neck Disability Index Score (NDIS) to measure disability. The data were collected before and after the intervention protocols. Statistical analysis was done using software SPSS16 Version In both groups Wilcoxon Signed Rank Test was used to compare pre-and posttest 
values. The post test scores of both groups were analysed using Mann Whitney U Test.

VAS is a reliable tool to assess patient's pain. Bijur PE et $\mathrm{al}^{24}$ in a study concluded that VAS is sufficiently reliable to be used to assess acute pain. Boonstra AM et $\mathrm{al}^{25}$ in another study also proved the good reliability of VAS.

Based on the statistical analysis in Swissball training group (group A) the pretest mean with standard deviation of VAS was $6.90 \pm 0.949$ and of posttest was $3.47 \pm .694$. the $z$ value was 3.455 and $P$ value was 0.00 . The result of the study shows that there is statistically significant difference between pretest and posttest values of VAS in swiss ball training group. Based on the statistical analysis Pressure biofeedback training group (group B) the pretest mean with standard deviation of VAS was $6.73 \pm .821$ and of posttest was $2.57 \pm .753$. The $z$ value was -3.436 and $P$ value was 0.00 . The result of the study shows that there is statistically significant difference between pretest and posttest values of VAS in Pressure biofeedback training group. While comparing Swissball training group and pressure biofeedback training group the mean rank of swiss ball training group was19.90 and for pressure biofeedback training group was 11.10. The sum of ranks of Swissball training group was 298.50 and for pressure biofeedback group was 166.50 . The Mann Whitney $U$ value was 46.50 and the $P$ value was 0.004 . The result of the study shows that there is significant difference between posttest mean rank of VAS in two groups. The posttest mean rank of VAS shows that pressure biofeedback training group (group B) shows significant improvement in pain than Swissball training group (group A).

Birgitta Helmerson Ackelman et a ${ }^{26}$ found that the modified version of the NDI is a valid and reliable instrument to measure disability due to neck pain. Similar study by Vernon $\mathrm{H}$ et $\mathrm{al}^{27}$ demonstrated that the NDI achieved a high degree of reliability and internal consistency. Based on the statistical analysis in Swissball training group (group A) the pretest mean with standard deviation of NDIS was $16.60 \pm 1.682$ and of posttest was $11.27 \pm 2.219$. The $z$ value was -3.438 and $P$ value was 0.00 . The result of this study shows that there is statistically significant difference between the pretest and posttest values of NDIS in swiss ball training group. Based on the statistical analysis Pressure biofeedback training group (group B) the pretest mean with standard deviation of NDIS was $19.33 \pm 2.820$ and of posttest was $7.93 \pm 2.604$. The $z$ value was -3.421 and $P$ value was 0.00 . The result of this study shows that there is statistically significant difference between the pretest and posttest values of NDIS in Pressure biofeedback training group. While comparing Swissball training group and pressure biofeedback training group the mean rank of swiss ball training group was 20.43 and for pressure biofeedback training group was 10.57. The sum of ranks of Swissball training group was 306.50 and for pressure biofeedback group was 158.50 . The Mann Whitney $U$ value was 38.50 and the $P$ value was 0.001 . The result of the study shows that there is significant difference between posttest mean rank of NDIS in two groups. The posttest mean rank of NDIS shows that pressure biofeedback training group (group B) shows significant improvement in functional disability than Swissball training group (group A).

In this study goniometer was used to measure mobility. Studies done by Muhammad Nazim Farooq et $\mathrm{al}^{28}$, James $\mathrm{W}$ Youdas et $\mathrm{al}^{22}$, Babatunde Olusola Adeleke Adegoke et $\mathrm{al}^{30}$ proved good to high intrarater and interrated reliability of goniometer for assessing active cervical range of motion.

The statistical result of the study showed that there is significant change in the cervical ROM in the swiss ball training group with the mean difference of standard deviation being 10.67 for cervical flexion, 9.13 for extension, 23.67 for right rotation, and 24.53 for left rotation. The $p$ value was 0.00 . The statistical result also showed that there is significant difference in the cervical ROM in the pressure biofeedback training group with the mean difference of 
standard deviation being 15 for cervical flexion, 18.26 for extension, 30.47 for right rotation, and 1.998 for left rotation. The $p$ value was 0.00 . while comparing swiss ball training group and pressure biofeedback training group the Mann whitney $U$ value was 182.00 and the $p$ value was 0.035 for cervical flexion, 14.00 and 0.00 for extension, 57.50 and 0.021 for right rotation and 53.50 and 0.013 for left rotation. These results showed that pressure biofeedback group showed significant improvement in mobility than swiss ball training group.

The result showed that after 6 weeks of treatment both groups shows significant improvement in pain, mobility and disability. From the Mann whitney $U$ test, the mean rank and sum of rank values concluded that pressure biofeedback training is more effective than swissball training in reducing pain, improving mobility and improving functional ability in computer professionals with nonspecific neck pain.

\section{Limitation of the study}

The study did not find a long-term effect of both pressure biofeedback training and Swiss ball training and the follow up could not be done.

\section{Recommendations for further study}

Scope of the future study arises to know the long-term effects of pressure biofeedback training and Swiss ball training.

\section{CONCLUSION}

The present study concludes that pressure biofeedback training is better when compared to Swiss ball training in nonspecific neck pain of computer professionals.

Based on the statistical analysis, the result of this study showed that there is significant difference in pain, mobility and functional disability between pretest and posttest groups in both Swiss ball training and pressure biofeedback training. Pressure biofeedback training group showed greater reduction in pain while analysing VAS score, improvement in mobility while measuring ROM using goniometer and improvement in functional ability while measuring Neck Disability Index Score than Swiss ball training group.

After analysing this study, we concluded that Pressure biofeedback training is very effective treatment technique for nonspecific neck pain as it reduced pain, improved mobility and increased the functional ability of the computer professionals when compared to Swiss ball training. Hence the pressure biofeedback training can be included in the rehabilitation program of patients suffering from nonspecific neck pain.

\section{REFERENCES}

1. Dr. S A Shah., et al (2015). Prevalence of neck pain in computer operators. NHL Journal of Medical Sciences. Vol 4 (issue 1).

2. Stupar M, Shearer $H$, Cote $P$ (2008). Prevalence and factor associated with neck pain in office workers. In: Proceeding of the World congress on the Neck pain; Los angeles. Toronto: Canadian Institute for the relief of pain and Disability:154.

3. Moore MK (2004). Upper crossed syndrome and its relationship to cervicogenic headache. J Manipulative Physiol Ther. 27: 414-420.

4. Szeto GP, Straker LM, O'Sullivan PB (2005). A comparison of symptomatic and asymptomatic office workers performing monotonous keyboard work-2: neck and shoulder kinematics. Man Ther. 10: 281291.

5. Yip $\mathrm{CH}$, Chiu TT, Poon AT (2008). The relationship between head posture and severity and disability of patients with neck pain. Man Ther. 13: 148-154.

6. Lehman GJ, Hoda W, Oliver S (2005). Trunk muscle activity during bridging exercises on and off a Swiss ball. Chiropr Osteopat. 13: 14.

7. Lee MY, LeeHY, Yong MS (2014). Characteristics of cervical position sense 
insubjects with forward head posture.J Phys Ther Sci. 26: 1741-1743.

8. Iqbal ZA, Rajan R, Khan SA, et al (2013). Effect of deep cervical flexor muscles training using pressure biofeedback on pain and disability of school teachers withneck pain. J Phys Ther Sci. 25: 657-661.

9. Gupta BD, Aggarwal S, Gupta B, et al (2013). Effect of deep cervical flexor training vs. conventional isometric training on forward head posture, pain, neck disability index in dentists suffering from chronic neck pain. J Clin Diagn Res. 7: 2261-2264.

10. Waly SM, Ozdomar O, Kline J, Asfour SS, Khalil TM (1986). The role of feedback information in isometric muscle training. Proc. 39th Annual Conf Engineering in Medicine and Biology, Baltimore, Marylar: p. 35

11. Falla D, Bilenkij G, Jull G (2004). Patients with chronic neck pain demonstrates altered patterns of muscle activation during performance of a functional upper limb task. Spine. 29: 1436-1440.

12. FallaD, JullG, Hodges PW (2004). Feed forward activity of the cervical flexor muscles during voluntary arm movements is delayed in chronic neck pain. Exp Brain Res 157: 43-48.

13. Janda V (1994): Muscles and motor control in cervicogenic disorders: assessment and Management. In: Physical therapy of the cervical and thoracic spine. 2nd ed. New York: Churchill Livingstone: pp 195-216.

14. Harrison DE, Harrison DD, Betz JJ, et al (2003). Increasing the cervical lordosis with chiropractic biophysics seated combined extension-compression and transverse load cervical traction with cervical manipulation: nonrandomized clinical control trial. J Manipulative Physiol Ther. 26: 139-151.

15. Borisut $S$, Vongsirinavarat $M$, Vachalathiti $R$, et al (2013). Effects of strength and endurance training of superficial and deep neck muscles on muscle activities and pain levels of females with chronic neck pain. J Phys Ther.Sci. 25: 1157-1162.
16. Winters JM, Peles JD (1990). Neck muscle activity and 3D head kinematics during static and dynamic tracking movements. In: Winters JM, Woo SLY, eds. Multiple Muscle Systems: Biomechanics and Movement Organization. New York: Springer-Verlag: 46180.

17. Falla D, Jull G, Russell T, et al (2007). Effect of neck exercise on sitting posture in patients with chronic neck pain. Phys Ther. 87: 408-417.

18. Md. Nezamuddin_, Shahnawaz Anwer, Sohrab Ahmad khan and Ameed Equebal (2012). Efficacy of pressure-biofeedback guided deep cervical flexor training on neck pain and muscle performance in visual display terminal operators. Journal of Musculoskeletal Research. Vol. 16, (No. 3)

19. Jeoung-Ah Ahn,, Joong-Hwi Kim, Anthony L Bendik,Ju-Yong Shin (2015). Effects of stabilization exercises with a Swiss ball on neck-shoulder pain and mobility of adults with prolonged exposure to VDTs. J. Phys. Ther. Sci. 27: 981-984.

20. Zaheen Ahmed Iqbal, et al (2013). Effect of Deep Cervical Flexor Muscles Training Using Pressure Biofeedback on Pain and Disability of School Teachers with Neck Pain. J. Phys. Ther. Sci. 25: 657-661.

21. Dong Yeon Kang (2015). Deep cervical flexor training with a pressure biofeedback unit is an effective method for maintaining neck mobility and muscular endurance in college students with forward head posture. J. Phys. Ther. Sci. 27: 3207-3210.

22. Myoung-Hyo Lee (2013). Effects of Neck Exercise on High-School Students' NeckShoulder Posture. J. Phys. Ther. Sci. 25: 571-574.

23. Hye-Young Cho, et al (2015). The Effect of Swiss Ball Stabilisation Exercise on Deep and Superficial Cervical Muscle and Pain in Patients with Chronic Neck Pain. Indian Journal of Science and Technology. Vol 8(S1): 14-19.

24. Polly E. Bijur, Wendy Silver, E. John Gallagher (2001). Reliability of the Visual Analog Scale for Measurement of Acute 
Pain. Academic Emergency Medicine. Volume 8, Number 12.

25. Boonstra AM, Schiphorst Preuper HR, Reneman MF, Posthumus JB, Stewart RE (2008). Reliability and validity of the visual analogue scale for disability in patients with chronic musculoskeletal pain. Int J Rehabil Res. 31(2):165-9.

26. Birgitta Helmerson Ackelman and Urban Lindgren (2002). Validity And Reliability Of A Modified Version Of The Neck Disability Index. J Rehabil Med. 34: 284-287.

27. Vernon H, Mior S. (1991). The Neck Disability Index: a study of reliability and validity. J Manipulative Physiol Ther. 14(7) :409-15.

28. Farooq MN, Mohseni Bandpei MA, Ali M, Khan GA (2016). Reliability of the universal goniometer for assessing active cervical range of motion in asymptomatic healthy persons. Pak J Med Sci. 32(2):457-461.

29. James W Youdas, James R Carey, Tom R Garrett (1990). Reliability of Measurements of Cervical Spine Range of Motioncomparison of Three Methods. Physical Therapy. Volume 71.
30. Babatunde Olusola Adeleke Adegoke et al (2015). Intra-Rater Reliabilities And Concurrent Validity of The Universal Goniometer And Tape Measure For Measuring Cervical Active Range of Motion. Journal of Musculoskeletal Research. Volume 18 (Issue 01).

31. Jin Young Kim \& Kwang II Kwag. Clinical effects of deep cervical flexor muscle activation in patients with chronic neck pain. J.Phys. Ther. Sci. 2016 28: 269-273.

32. Aysha Siddiqua Kalim Khan, Mohammed Faizan (2016). Neck pain in computer users. Panacea Journal of Medical Sciences. 6(2): 88-9.

33. Bhojan Kannabiran (2016). A Comparative Study between Combinations of Ultrasound Therapy with Active Chin Tuck Exercise and Ultrasound Therapy with Sub Occipital Muscle Release in the Management of Non-Specific Neck Pain due to Sub Occipital Muscle Tightness among Computer Professionals. MOJ Orthop Rheumatol., 5(2): 00173.

\section{Citation:}

Parvathy.S,Vaishali Sreejith. A comparative study between the efficacy of swiss ball exercise v/s pressure biofeedback training on pain, mobility and functional disability in computer professionals with non specific neck pain , IJMAES, 2017; 3 (3), 379-389. 